\title{
Technology transfer on the table
}

\section{Climate summit will seek ways to help developing nations build a low-carbon energy infrastructure.}

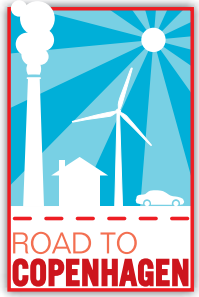

Cutting global carbon emissions and slowing climate change will require a massive dissemination of clean-energy technology from rich nations to the developing world. And although negotiators remain deadlocked over goals for cutting emissions (see page 550), they are converging on a framework for speeding up the spread of the necessary technologies.

Several proposals for this will be on the table when delegates from 192 countries gather in Copenhagen for the climate summit next week, but two elements seem to be gathering momentum in the run-up discussions. The first is the idea of a centralized technology-transfer body under the United Nations climate convention. The second is a network of regional centres, or some kind of technology corps, to help poor nations implement sustainabledevelopment plans.

Both proposals sidestep the issue of access to patented technology, the focus of a long-running dispute between rich and poor nations. Instead, they would help poor countries address an array of mundane but in many ways more pernicious issues, such as energy infrastructure, government policy and workforce development, that hinder their ability to absorb new technologies. Blueprints for a solar thermal power station, for instance, aren't much use without qualified engineers to build and run it and power lines to carry the electricity - challenges even for industrialized nations.

"You have to come back to the basic question about how technology is flowing to the developing world, and it's primarily flowing through transactions within the business community," says Björn Stigson, president of the World Business Council for Sustainable Development in Geneva, Switzerland. Government policies, local economics and workforce issues can all affect those deals, he says. "The biggest bottleneck is availability of human resources."

Exactly how this new framework would function, what kind of authority it would have and how much money it would command remain to be worked out. But poor and rich countries alike support the general idea, says Kunihiko Shimada, a Japanese delegate who

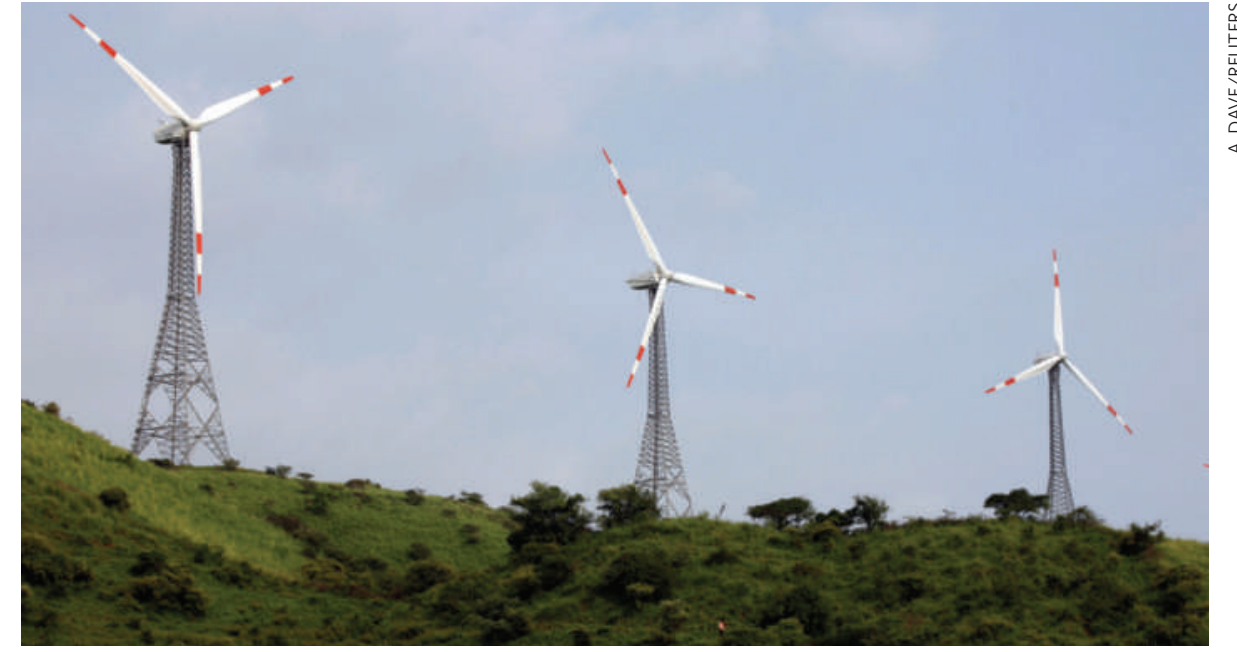

To tackle climate change, poor countries may need green technologies, such as these wind turbines in India.

has stepped aside as a negotiator in order to co-chair the technology-transfer group at the UN climate talks.

Shimada acknowledges that negotiators in Copenhagen could still get bogged down in the debate over access to the patented technologies found in everything from the latest solar panels to low-emission coal-plant prototypes. Developing countries have to varying degrees called for compulsory licensing, which would force companies to put certain patents in the public domain, or for a fund to purchase patented technologies, which would then be put in the public sphere. Industrialized countries are resisting such proposals, declaring that intellectual property is crucial to driving innovation.

In fact, little is known about how patents affect technological diffusion in the energy industry, when any given 'technology', such as a wind turbine or a clean coal plant, might contain dozens or hundreds of patents, many of which originated in other industries. "We are flying blind," says Bernice Lee, a researcher who has been studying the issue at Chatham House, a think tank in London.

Lee recently headed a Chatham House analysis of nearly 57,000 patents in six energy sectors, which found that the 30 most-cited patents in each sector took two to three decades to hit the mass market. That lag time will need to be halved by 2025 if the world is to meet its climate goals, according to the report.
In order to disperse crucial technologies more quickly and widely, Chatham House recommends expanding global demonstration programmes for high-risk sectors such as carbon capture and storage, coordinating technology standards, and accelerating international collaboration on research and development.

All of these functions could be promoted through a technology-transfer body under the UN climate convention, although few think that will be enough to get the job done. "We need a proliferation of efforts and institutions, because we don't know what is going to work," says Michael Levi, a climate expert at the Council on Foreign Relations in New York City. "What we can't afford is to focus on a single mechanism and then find out over the course of a decade that it doesn't work very well."

The developing world, for its part, can't simply wait for the rich countries to equip it for a low-carbon future, says Shane Tomlinson, a researcher with the London-based advocacy group E3G, which promotes sustainable development. One proposal under discussion would require countries to create their own sustainable-development strategies, perhaps in concert with plans for adapting to climate change, to be eligible for international aid. "It's a balanced approach between top-down strategic prioritization and bottom-up low-carbon development plans that is really key to getting the marketplace right," Tomlinson says. "We really do need both."

Jeff Tollefson

For more, see www.nature.com/roadtocopenhagen. 